\title{
Regulation of gene expression for defensins and lipid transfer protein in Scots pine seedlings by necrotrophic pathogen Alternaria alternata (Fr.)
}

\author{
Nataliya Hrunyk, Roman Gout, Valentina Kovaleva $\bowtie$ \\ Ukrainian National Forestry University, Forest Department, Gen. Chuprynky 103, 79057 Lviv, Ukraine, \\ phone: +380322379523, e-mail: kovaleva@nltu.edu.ua
}

\begin{abstract}
Damping-off disease in pine seedling, caused by fungi and oomycetes (Fusarium, Alternaria, Botrytis, Phytophthora) and other species, is one of the most dangerous diseases in conifer nurseries and greenhouses worldwide. Alternaria alternata is a necrotrophic pathogen, which causes early blight in higher plants and results in massive economic losses in agro-industry as well as in forestry. Pine seedlings that lack strong lignificated and suberized cell walls at early stages of their growth are vulnerable to damping-off disease. So, triggering the synthesis of antimicrobial compounds, such as phytoalexins, anticipins and pathogenesis-related (PR) proteins, is the main defense strategy to confine pathogens at early stages of pine ontogenesis. Defensins and lipid transfer proteins are members of two PR-protein families (PR-12 and PR-14 respectively) and possess antimicrobial activities in vitro through contact toxicity, and the involvement in defense signalling. In this work, we describe the changes in the expression levels of four defensin genes and lipid transfer protein in Scots pine seedlings infected with $A$. alternata. The expression levels of PsDef1 and PsDef2 increased at 48 h.p.i. (hours post inoculation). The levels of PsDef4 transcripts have increased after 6 and 24 hours. Notably, at 48 h.p.i., the level of PsDef4 transcripts was decreased by 1.2 times compared to control. The level of $P_{s} D e f 3$ transcripts was reduced at all three time points. On the other hand, the level of PSLTP1 transcripts increased at $6 \mathrm{~h}$ and 48 h.p.i.; while at 24 h.p.i., it decreased by $20 \%$ when compared to the control sample. Our results suggest that defensins and lipid transfer protein are involved in the defense response of young Scots pine to necrotrophic pathogen. Thus, those genes can be used as the molecular markers in forestry selection and development of the ecologically friendly remedies for coniferous seedlings cultivation in greenhouses and nurseries.
\end{abstract}

\section{KEY WORDS}

Alternaria alternata, damping-off disease, defensins, expression, lipid transfer protein, Scots pine seedling 


\section{INTRODUCTION}

For the implementation of large-scale projects on afforestation and reforestation, it is necessary to grow a significant number of high-quality seedlings in forest nurseries. Damping-off is a common disease problem in forest nurseries during the first few weeks after sowing. Nowadays, there is an urgent need to develop the environmentally friendly methods for the protection of woody plants from pathogens based on the knowledge of natural plant resistance mechanisms, in analogy for the protection of crops. These technologies are based on the management of plant immunity, selection of resistant genotypes by molecular markers and obtaining the genetically modified plants. The work in this direction in forestry has only started to progress.

The molecular mechanisms of pathogen defense and resistance are well established in a model plant Arabidopsis thaliana and horticultural crops, but plant-pathogen interactions in trees remain largely unexplained (Franceschi et al. 2005). Scots pine exhibits a range of constitutive and inductive defense responses, including the induction of traumatic resin ducts, lignification of infected tissues and production of other antimicrobial compounds, including PR (pathogenesis-related) proteins (Pearce 1996; Eyles et al. 2010). The expression of PR-proteins is a key mechanism of pine seedling defense against pathogens, because the lack of powerful mechanical barriers cannot provide required protection against infection (Adomas 2007; Kovaleva et al. 2009; Sooriyaarachchi et al. 2011).

Alternaria alternata is one of the causative agents of early blight in pine seedlings (Huang and Kuhlman 1990; Baranov et al. 2010). It is well established that the inoculation of Arabidopsis with the Alternaria brassicicola results in differential expression of five defensin genes (Tesfaye et al. 2013). But the expression of PR-proteins in pine seedlings, infected with $A$. alternata, is not studied at the transcription level. We previously reported the purification of the two antimicrobial proteins, defensin 1 and lipid-transfer protein, from the pine seedlings and showed their antifungal activity against $A$. alternata (Kovaleva et al. 2009). In addition, we cloned several defensins genes PsDefl ( $P$ inus sylvestris Defensin 1) (Kovalyova et al. 2007), PsDef2 (Kovalyova and Gout 2008) PsDef3, PsDef4 and PSLTP1 (Pinus sylvestris lipid transfer protein 1) and demonstrated that these genes are expressed at early stages of postembryonic development in Scots pine (Yusypovych et al. 2011; Hrunyk et al. 2012).

Plant defensins are small basic secretory proteins, which possess inhibitory activities against fungi and bacteria. Besides antifungal and antibacterial properties, some plant defensins are able to regulate cellular enzymes and processes, including serine proteinases and $\alpha$-amylases, and $\mathrm{Ca}^{2+}$ and $\mathrm{Na}^{+}$channels and protein translation. They also exhibit activities against parasitic plants and heavy metal tolerance. The genes encoding plant defensins are expressed constitutively in the peripheral cell layers forming the first defensive line against pathogens (Thomma et al. 2002; Carvalho and Gomes 2009).

Plant lipid transfer proteins are small basic proteins, which are able to bind hydrophobic compounds in vitro and encoded by large multigene families (Carvalho and Gomes 2007; Kader et al. 2007; Edstam et al. 2011). LTPs are involved in key processes in plant physiology, such as cell wall organization, stabilization of membranes, signal transduction, plant growth and development (sexual reproduction, seed development and germination) (Nielsen et al. 1996; Maldonado et al. 2002). LTPs are also known to play a role in resistance to biotic stress (Sels et al. 2008). The expression of LTP after the infection with pathogens was a benchmark for their classification as PR-proteins.

In this work, our aim was to establish the transcriptional profiling of PsDef1-4 and PsLTP1 genes in tissues, with the use of semiquantitative multiplex RTPCR (mxPCR), after inoculation of Scots pine with Alternaria alternata.

\section{Material and Methods}

\section{Plant and fungal materials}

Seeds of Scots pine (Pinus sylvestris L.) were obtained from Lviv forest breeding seed centre (Lviv region, Ukraine). Surface-sterilized seeds were germinated on Whatman paper soaked with distilled water in Petri dishes at $26^{\circ} \mathrm{C}$ in the thermostat. After 7 days, the seedlings were used for inoculation.

A culture of fungal pathogen Alternaria alternata UKM F-16752 was obtained from D.K. Zabolotny Institute of Microbiology and Virology, Ukraine. Fungal 
cultures were grown in potato dextrose broth for 7 days at $22^{\circ} \mathrm{C}$ and then the mycelium was washed with sterile water and subsequently blended with Ultra-Turrax T-25 homogenizer.

\section{Inoculation experiments}

Twenty seedlings of $P$. sylvestris were transferred to wet, sterile filter paper in Petri dishes. The roots were inoculated with $1 \mathrm{ml}$ of the homogenized mycelium and covered with a second layer of moist sterile filter paper. Control seedlings were treated with $1 \mathrm{ml}$ of sterile distilled water. The seedlings of either infected or control plants were harvested at 6,24 and $48 \mathrm{~h}$ post inoculation (h.p.i.), immediately frozen in liquid nitrogen and stored at $-70^{\circ} \mathrm{C}$ until use. The infection development was observed in stereoscopic microscope MBS-9. The experiments were repeated in triplicates.

Table 1. Primers used in this study

\begin{tabular}{|c|c|c|c|}
\hline Gen & Primer sequence $\left(5^{\prime}-3^{\prime}\right)$ & $\begin{array}{l}\text { Product's } \\
\text { size }(b p)\end{array}$ & $\begin{array}{c}\text { GenBank } \\
\text { accession } \\
\text { no. }\end{array}$ \\
\hline \multirow{2}{*}{ PsDef1 } & $\begin{array}{c}\text { GGGATGATGCAGGT- } \\
\text { TCAAGT }\end{array}$ & \multirow{2}{*}{159} & \multirow{2}{*}{ EF455616.1 } \\
\hline & $\begin{array}{l}\text { ACATTTTCTGC- } \\
\text { CAGCCACAT }\end{array}$ & & \\
\hline \multirow{2}{*}{ PsDef2 } & $\begin{array}{c}\text { TCCACTCAGTGCC- } \\
\text { CTTTTTC }\end{array}$ & \multirow{2}{*}{210} & \multirow{2}{*}{ EF455617.1 } \\
\hline & $\begin{array}{c}\text { ACCAGCCGA- } \\
\text { AAGTGCTACTG }\end{array}$ & & \\
\hline \multirow{2}{*}{ PsDef3 } & $\begin{array}{c}\text { AACCATTGGGAT- } \\
\text { GATGGC }\end{array}$ & \multirow{2}{*}{190} & \multirow{2}{*}{ JN980401.1 } \\
\hline & $\begin{array}{c}\text { GCACTTTCGGCTG- } \\
\text { GTGAC }\end{array}$ & & \\
\hline \multirow{2}{*}{ PsDef4 } & $\begin{array}{c}\text { TGTGCTGCTCGTGT- } \\
\text { TAG }\end{array}$ & \multirow{2}{*}{145} & \multirow{2}{*}{ KJ601732.1 } \\
\hline & $\begin{array}{c}\text { CGTTGGAAACCCTT- } \\
\text { CAGTA }\end{array}$ & & \\
\hline \multirow{2}{*}{ PSLTP1 } & $\begin{array}{c}\text { ATGGCTGTGAAGA- } \\
\text { AGATG }\end{array}$ & \multirow{2}{*}{372} & \multirow{2}{*}{ JN980402.1 } \\
\hline & $\begin{array}{c}\text { TCAGTGAACCTTG- } \\
\text { GAACAG }\end{array}$ & & \\
\hline \multirow{2}{*}{$R P L 44$} & $\begin{array}{l}\text { CAAAGCTTGCA- } \\
\text { AAAAGCACA }\end{array}$ & \multirow{2}{*}{263} & \multirow{2}{*}{ EL342388.1 } \\
\hline & $\begin{array}{c}\text { TTCCCTTCCCCTTCT- } \\
\text { TGTCT }\end{array}$ & & \\
\hline
\end{tabular}

\section{Semiquantitative multiplex RT- PCR analysis of gene transcription}

Expression of PSLTPI and PsDefl-4 genes was carried out using $\mathrm{mxPCR}$. Total RNA was obtained using a modified method of lithium-chloride precipitation by Chang (Chang et al. 1993). The cDNA sample was synthesized from $1 \mu \mathrm{g}$ of total RNA using RevertAid ${ }^{\mathrm{TM}}$ Premium reverse transcriptase (Fermentas). After first strand cDNA synthesis, the cDNA sample was used as a template for $\mathrm{mxPCR}$. Each reaction mixture contained 2 pairs of primers: gene-specific and a reference gene RPL 44 [60S ribosomal protein L44 (GenBank Acc. No. EL342388)] to assess the efficiency of amplification and for the calculation of relative values of the expression levels. The primer sequences used in mxPCR are shown in Table 1. PCR was run for 30 cycles in a thermal cycler MultiGene II (LabNet International, Inc.) using the program: $95^{\circ} \mathrm{C}, 45 \mathrm{~s} ; 54^{\circ} \mathrm{C}, 45 \mathrm{~s} ; 72^{\circ} \mathrm{C}, 45 \mathrm{~s}$. The PCR products were separated by electrophoresis on a $2.0 \%$ agarose gel and visualized with ethidium bromide staining and photographed. Densitometry analysis was run with Software Gel-Pro Analyzer 4.0.

\section{Results ANd Discussion}

Damping-off disease in pine seedling, caused by fungi and oomycetes (Fusarium, Alternaria, Botrytis, Phytophthora) and other species, is one of the most dangerous diseases in conifer nurseries and greenhouses worldwide (Hocking and Jaffer 1969). Pine seedlings are vulnerable to vascular infections due to the weakness of the mechanical protection systems, because of the lack of strong lignificated and suberized cell walls. Pathogen attack triggers the signal transduction cascades regulated by salicylic acid, jasmonic acid and ethylene, resulting in the production of antimicrobial secondary metabolites, and the expression of genes encoding PR proteins, which possess antimicrobial activities in vitro through hydrolysing cell walls, contact toxicity and the involvement in defense signalling (van Loon et al. 2006).

A. alternata is a causative agent of early blight in higher plants, which leads to significant economic losses in agro-industry as well as in forestry. The pathogen belongs to the ascomycetous fungi and leads a necrotrophic lifestyle. To date, the molecular events in the 
host-pathogen system Arabidopsis - Alternaria brassicicola are well studied. A well-established marker for the defense response in Arabidopsis is the PDF1.2 gene that encodes a defensin peptide (Penninckx et al. 1996). It has been previously reported that Scots pine defensin PsDef1 has the potential to inhibit growth of A. alternata at the concentration below $1 \mu \mathrm{M}$ (Kovaleva et al. 2009). However, the induction of PsDef1 expression by this pathogen has not been investigated so far.

To check the pathogenicity effect of A. alternata on pine seedlings, we monitored the morphological changes in inoculated seedlings within eight days. On the first three days, there were no visible signs of pathogen infection. The first obvious signs of infection were detectable on the fifth day of post inoculation period. The colour of hypocotyls became slightly brownish and seedlings lost the turgor, when compared to control samples (Fig. 1). The growth of mycelium on roots and hypocotyls was observed for 8 days. At day 7, the infection spread to the base of cotyledons and the mycelium colonized the whole plant at day 8 .

The expression patterns of Scots pine defensin genes and PSLTP1 were investigated on earlier stages of the infection process. This study revealed that four defensin genes showed differential expression at tested time points. The levels of PsDef1 and PsDef2 transcripts increased at 48 h.p.i. by 5.5 and 1.5 times respectively (Fig. 2). The expression of PsDef4 has increased by 1.3 times at 6 h.p.i. and after 24 h.p.i. the increase was even more evident; it was 3 times. This upregulation was transient and the expression reduced to 1.2 times at 48 h.p.i., when compared to control. Interestingly, PsDef 3 showed slightly reduced expression at all three time points. Our data reveal differential and time-coordinated expression of defensin genes in Scots pine in response to pathogen attack of necrotrophic fungus. Remarkably, the pattern of defensin gene expression resembles that described for infected Arabidopsis (Schenk et al. 2003). In a time-course study, it was found that inoculation with $A$. brassicicola results in the induction of PDF1.2 at earlier stages (6 to 12 h.p.i.). Notably, the highest induction of PDF1.2 was observed at 72 h.p.i. for both local and distal tissues. It has been demonstrated that basal resistance of Arabidopsis to this pathogen involves the jasmonate/ethylene pathway (Glazebrook 2005). We have previously shown that exogenous jasmonic acid significantly induces the expression of PsDef1, PsDef2 and PsDef4 genes in pine seedlings (Shalovylo et al. 2015). These findings suggest the existence of conservative defense mechanisms in gymnosperms, and angiosperms followed the infection by necrotrophic pathogens.

Alternaria also affects the expression of PSLTP1 in young pine seedlings. It was shown that the level of PSLTP1 transcripts was increased at $6 \mathrm{~h}$ and 48 h.p.i., by 1.9 and 2.1 times respectively. However, at 24 h.p.i. the expression was decreased by $20 \%$ in comparison to control samples. At earlier stages of pathogen infiltration, plant immunity initiates the first layer of
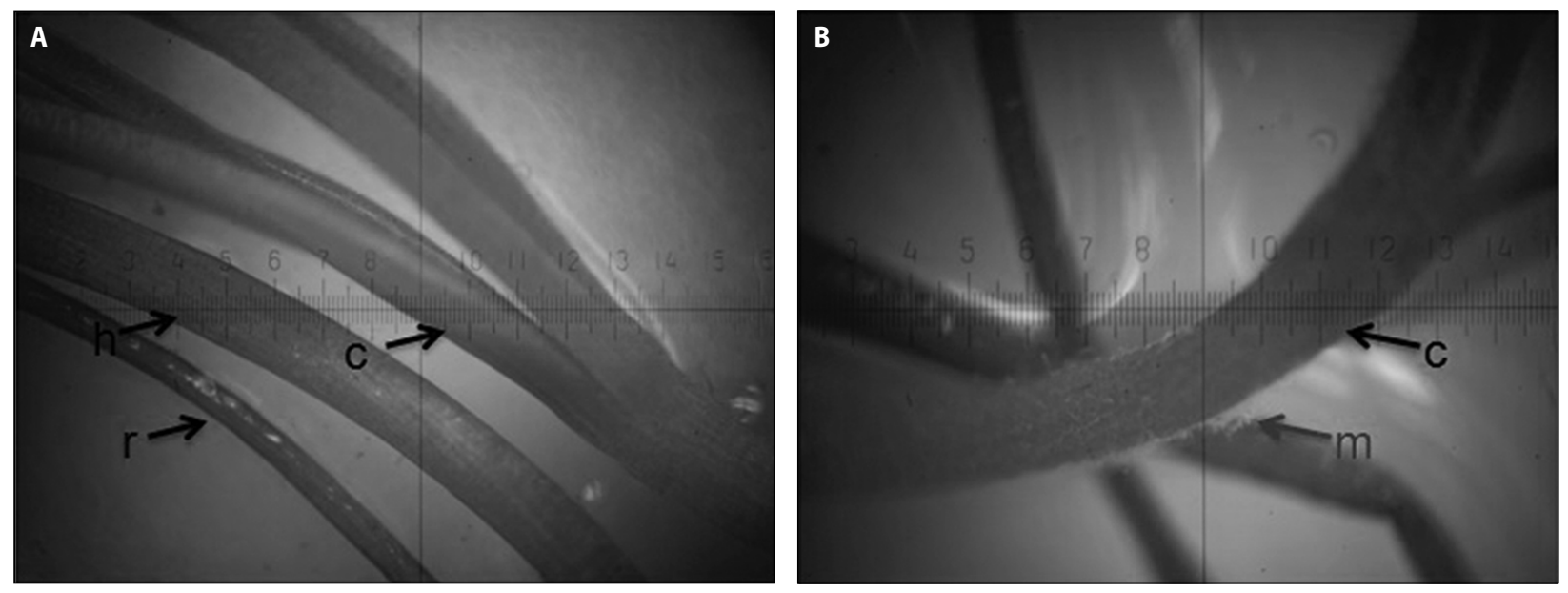

Figure 1. Uninoculated (A) and 8 days infected Scots pine seedlings by Alternaria alternata (B). Abbreviations: c - cotyledon; $\mathrm{h}$ - hypocotyl; $\mathrm{r}$ - root; $\mathrm{m}$ - mycelium. (Magnification 16x) 
A
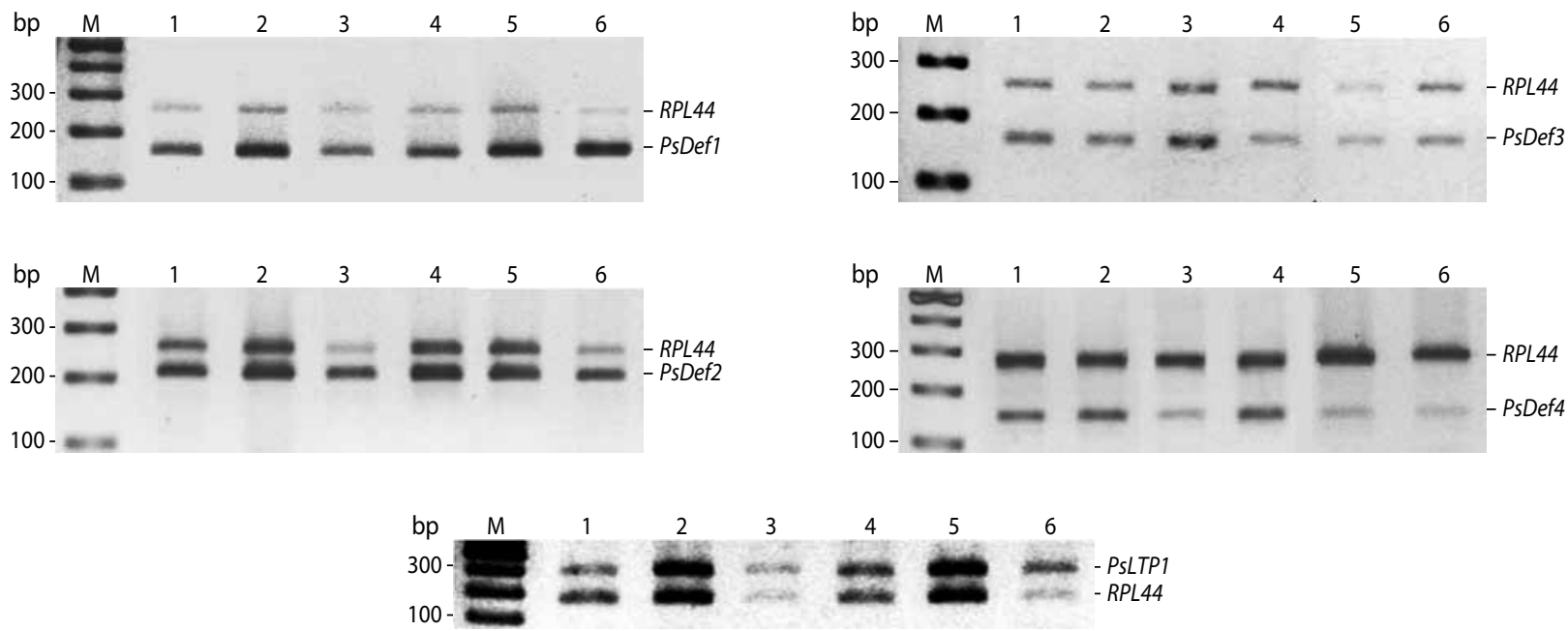

B

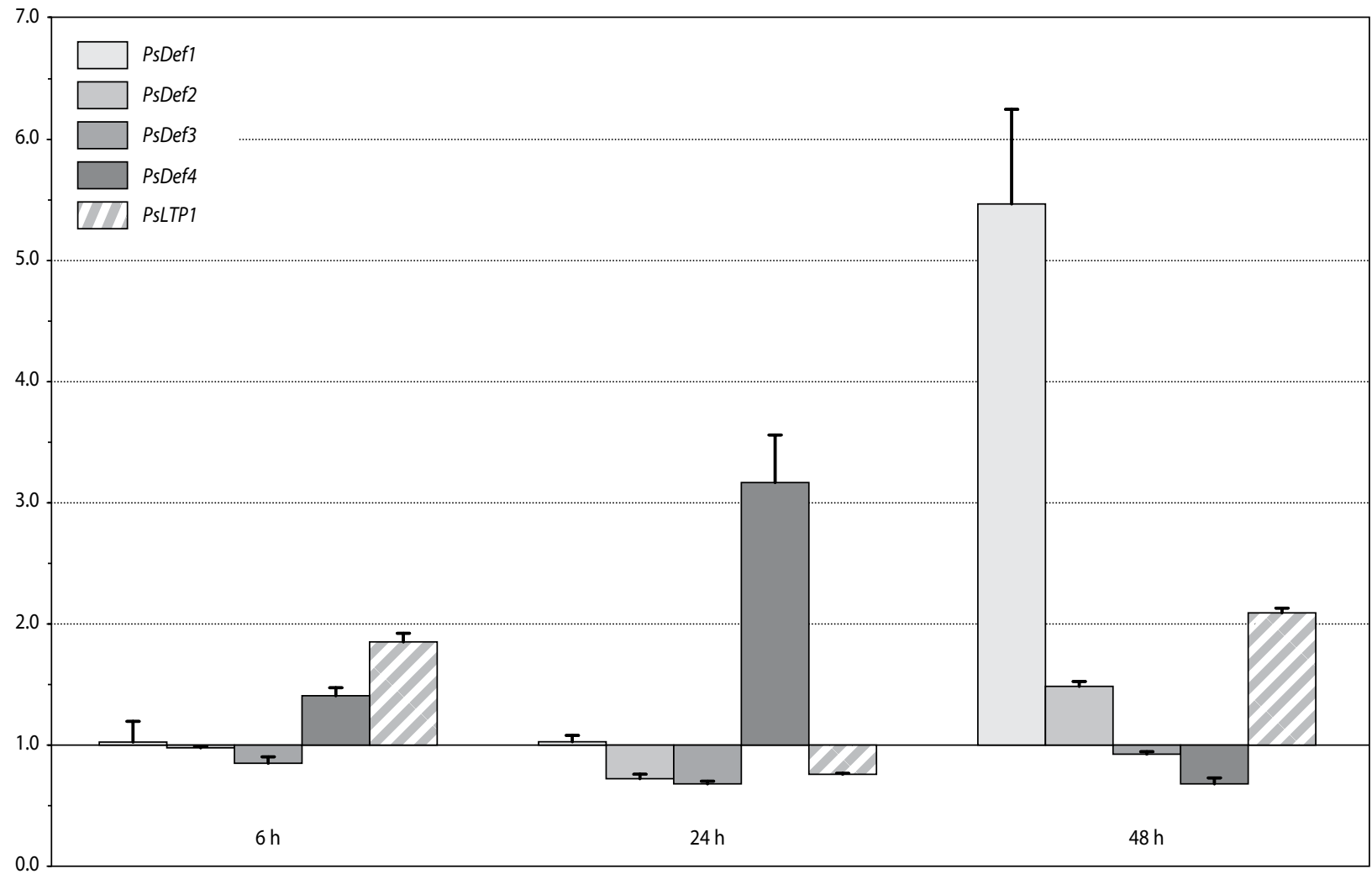

Figure 2. Analysis of PSLTPI and defensins expression in Scots pine seedlings, inoculated with A. alternata and collected after 6, 24 and 48 hours. A - electrophoregram of the mxPCR products obtained from RNA of pine seedlings inoculated with mycelium of $A$. alternata $(2-6$ h.p.i., $4-24$ h.p.i. and $6-48$ h.p.i.), and control seedlings $(1-6$ h.p.i., $3-24$ h.p.i. and $5-48$ h.p.i.). M - GeneRuler 100 bp Plus DNA Ladder (Fermentas). Right lines indicate the PCR-products: PsLTP1, PsDef1, PsDef2, PsDef3, PsDef4 and "house-keeping" gene RPL44. B - The values of the expression level of PsLTP1, PsDef1, PsDef2, PsDef3, PsDef4 calculated relative to RPL44. The expression level of these genes in control seedlings was set to one 
defense mechanism, involving the activation of weak but broad-spectrum immune response (Laluk and Mengiste 2010). The second layer of innate immunity involves the induction of host disease-resistance proteins, resulting in rapid and powerful response, known as a hypersensitive reaction (Heath 2000). We have previously demonstrated that PSLTP1 transcripts are expressed in young pine seedlings at high levels and their expression is regulated by plant hormones, such as abscisic acid, kinetin and heteroauxin (Hrunyk et al. 2012). The molecular mechanisms of the observed upregulation require further investigation. Due to the second wave of pathogen invasion, plant activates the defense shield, leading to the outburst of different PRproteins, including PSLTP1.

\section{Conclusions}

The findings presented in this study suggest that the expression pattern of PsDefl and PsLTP1 could be used for screening of Scots pine genotype for resistance towards necrotrophic pathogens, and also for the identification of immunity inductors and the development of ecologically friendly remedies of efficient cultivation of coniferous seedlings in greenhouses and nurseries.

\section{Acknowledgements}

The work on this project is funded from the Ministry of Education and Science of Ukraine.

\section{References}

Adomas A., Heller G., Li G., Olson Å., Chu T.M., Osborne J., Craig D., Zyl L.V., Wolfinger R., Sederoff R., Dean R.A., Stenlid J., Finlay R., Asiegbu F.O. 2007. Transcript profiling of a conifer pathosystem: response of Pinus sylvestris root tissues to pathogen (Heterobasidion annosum) invasion. Tree Physiology, 27, 1441-1458.

Baranov O.Yu., Oszako T., Nowakowska J.A., Panteleev S.V. 2010. Genetic identification of fungi colonising seedlings of the Scots pine (Pinus sylvestris L.) in the forest nursery in Korenevka (Belarus). Fo- lia Forestalia Polonica, Ser. A - Forestry, 52 (1), 61-64.

Carvalho A.O., Gomes V.M. 2007. Role of plant lipid transfer proteins in plant cell physiology - a concise review. Peptides, 28, 1144-1153.

Carvalho A.O., Gomes V.M. 2009. Plant defensins - prospects for the biological functions and biotechnological properties. Peptides, 30, 1007-1020.

Chang S., Puryear J., Cairney J. 1993. A simple and efficient method for isolating RNA from pine trees. Plant Molecular Biology Reporter, 11 (2), 113-116.

Edstam M.M., Viitanen L., Salminen T.A., Edqvist J. 2011. Evolutionary history of the non-specific lipid transfer proteins. Molecular Plant, 4 (6), 947-964.

Eyles E., Bonello P., Ganley R., Mohammed C. 2010. Induced resistance to pests and pathogens in trees. New Phytologist, 185, 893-908.

Franceschi V.R., Krokene P., Christiansen E., Krekling T. 2005. Anatomical and chemical defences of conifer bark beetles and other pests. New Phytologist, 167, 353-376.

Glazebrook J. 2005. Contrasting mechanisms of defense against biotrophic and necrotrophic pathogens. Annual Review of Phytopathology, 43, 205-227.

Heath M.C. 2000. Nonhost resistance and nonspecific plant defenses. Current Opinion in Plant Biology, 3, 315-319.

Hocking D., Jaffer A.A. 1969. Damping off in pine nurseries: fungicidal control by seed pelleting. Commonwealth Forestry Review, 48 (4) (138), $355-363$.

Hrunyk N.I., Kovaleva V.A., Gout. R.T. 2012. Patterns of expression of lipid-transfer protein gene in organs of Scots pine (Pinus sylvestris L.). Studia Biologica, 6 (2), 151-160.

Huang J.W., Kuhlman E.G. 1990. Fungi associated with damping-off of Slash pine seedlings in Georgia. Plant Disease, 74, 27-30.

Kader J.-C. 1996. Lipid transfer proteins in plants. Annual Review of Plant Physiology and Plant Molecular Biology, 47, 627-654.

Kovaleva V., Kiyamova R., Cramer R., Krynytskyy H., Gout I., Filonenko V., Gout R. 2009. Purification and molecular cloning of antimicrobial peptides from Scots pine seedlings. Peptides, 30, 2136-2143.

Kovalyova V.A., Gout I.T., Kiyamova R.G., Filonenko V.V., Gout R.T. 2007. Cloning and analysis of de- 
fensin 1 cDNA from Scots pine. Biopolymers and Cell, 23, 398-404.

Kovalyova V.A., Gout I.T. 2008. Molecular cloning and characterization of Scotch pine defensin 2. Cytology and genetics, 42 (6), 408-412.

Laluk K., Mengiste T. 2010. Necrotroph attacks on plants: wanton destruction or covert extortion? The Arabidopsis Book, 8, e0136.

Maldonado A.M., Doerner P., Dixonk R.A., Lamb C.J., Cameron R.K. 2002. A putative lipid transfer protein involved in systemic resistance signalling in Arabidopsis. Nature, 419 (6905), 399-403.

Nielsen K.K., Nielsen J.E., Madrid S.M., Mikkelsen J.D. 1996. New antifungal proteins from sugar beet (Beta vulgaris L.) showing homology to nonspecific lipid transfer proteins. Plant Molecular Biology, 31, 539-552.

Pearce R.B. 1996. Antimicrobial defenses in the wood of living trees. New Phytologist, 132, 203-233.

Penninckx I.A., Eggermont K., Terras F.R., Thomma B.P., De Samblanx G.W., Buchala A., Metraux J.P., Manners J.M., Broekaert W.F. 1996. Pathogen-induced systemic activation of a plant defensin gene in Arabidopsis follows a salicylic acid-independent pathway. Plant Cell, 8, 2309-2323.

Schenk P.M., Kazan K., Manners J.M., Anderson J.P., Simpson R.S., Wilson I.W., Somerville S.C. Maclean D.J. 2003. Systemic gene expression in Arabidopsis during an incompatible interaction with Alternaria brassicicola. Plant Physiology, 132, 999-1010.
Sels J., Mathys J., De Coninck B.M.A., Cammue B.P.A., De Bolle M.F.C. 2008. Plant pathogenesis-related (PR) proteins: A focus on PR peptides. Plant Physiology and Biochemistry, 46, 941-950.

Shalovylo Y.I., Yusypovych Y.M., Kovaleva V.A., Gout R.T. 2015. The effect of phytohormones on expression of defensin gene in Scots pine. Studia Biologica, 9 (1), 15-24.

Sooriyaarachchi S., Jaber E., Covarrubias A.S., Ubhayasekera W., Asiegbu F.O., Mowbray S.L. 2011. Expression and $\beta$-glucan binding properties of Scots pine (Pinus sylvestris L.) antimicrobial protein (Sp-AMP). Plant Molecular Biology, 77, $33-45$.

Tesfaye M., Silverstein K.A., Nallu S., Wang L., Botanga C.J., Gomez S.K., Costa L.M., Harrison M.J., Samac D.A., Glazebrook J., Katagiri F., GutierrezMarcos J.F., Vandenbosch K.A. 2013. Spatio-temporal expression patterns of Arabidopsis thaliana and Medicago truncatula defensin-like genes. PLoS One, 8 (3), e58992.

Thomma B.P., Cammue B.P., Thevissen K. 2002. Plant defensins. Planta, 216 (2), 193-202.

van Loon L.C., Rep M., Pieterse C.M.J. 2006. Significance of inducible defense-related proteins in infected plants. Annual Review of Phytopathology, 44, 135-162.

Yusypovych Y.M., Kovalyova V.A., Gout R.T. 2011. The organ-specific expression of defensins 1 (PsDef1) in Pinus sylvestris L. Scientific Bulletin of UNFU, 21 (3), 44-49. 